\title{
A national study of asthma in childhood
}

\author{
CATHERINE PECKHAM \\ From the Charing Cross Hospital Medical School, London
}

\author{
NEVILLE BUTLER \\ From the University of Bristol
}

SUMMARY A history of asthma was obtained in 3.5\% of a representative national sample of children aged 11 years. A further $8.8 \%$ had a history of wheezy bronchitis. In the 12 months before the interview, $2 \%$ had experienced attacks of asthma and a further $2.9 \%$ attacks of wheezy bronchitis. Both conditions were significantly more common among boys than girls, and a history of asthma was reported more frequently among children from non-manual than from manual social classes. Children with frequent attacks of wheezing had lower mean relative weights. A history of eczema and hay fever was more frequently discovered in children with reported asthma than in those with wheezy bronchitis, whereas migraine or recurrent headaches, recurrent abdominal pain, and recurrent throat or ear infections were more commonly associated with wheezy bronchitis than with asthma. The modified Rutter home behaviour scale, which reflects the parental view of the child's behaviour, was significantly raised among children with a history of wheezing, but their school behaviour as judged by the Bristol social adjustment guide showed no such difference. In spite of increased absence from school because of illness, no differences were found in educational attainment between children with a history of asthma or wheezy bronchitis and those with neither condition.

\section{Introduction}

Previous studies on asthma in childhood have been restricted mainly to local or selected samples from the population. The present study is an attempt to overcome the bias introduced by variations in size and characteristics of sample population by examining the prevalence of childhood asthma and wheezy bronchitis in a nationally representative sample of children. The nature of this sample has allowed comparisons to be made between the medical history, social background, and educational progress of children with a history of asthma and/or wheezy bronchitis and those who had no history of either complaint.

\section{Method}

Information has been compiled from the results of the National Child Development Study conducted by the National Children's Bureau. This study is a longitudinal survey of all children in England, Scotland, and Wales who were born in one week in March, 1958 (Davie et al., 1972). It originated from the 17000 children in the National Birthday Trust Fund's Perinatal Mortality Survey (Butler and Alberman, 1969). Medical, social and educational data were obtained from three main sources when the children were seven and 11 years old. Parents were interviewed in the home, school doctors carried out medical examinations, and teachers filled in a questionnaire at school. The children completed a number of tests and a questionnaire at the age of 11 .

The educational tests at the age of 11 included a reading comprehension test, developed along the lines of the Watts Vernon test (Start and Wells, 1972), an arithmetic test, and a test of general ability. These tests were constructed and standardised for children aged 11 by the National Foundation for Educational Research.

As a measure of the child's behaviour in the home, parents were asked about 17 'behaviour items' from the Rutter home behaviour scale (Rutter et al., 1970). Information on school behaviour was obtained from the Bristol social adjustment guide (Stott, 1963) which was completed for each child by the teacher. 


\section{Selection of children}

The health visitor asked parents of children aged 11 'Has your child ever had attacks of asthma; of wheezy bronchitis; or neither of these conditions'? If the answer to the first two questions was 'yes', parents were then asked about the frequency of attacks, categorised as follows: at least once a week; usually less than once a week but can expect one a month; at least one attack in past year but less frequently than once a month; had attacks in the past year but don't know frequency; no attacks at all in past year but had attacks when younger. The terms asthma and wheezy bronchitis were both included in the parental questionnaire since it is often difficult to distinguish precisely between them. However, a history of asthma has been shown to be a good indicator of impaired ventilatory function (Hamman et al., 1975), whereas bronchitis with associated wheezing has been less well validated, although recent evidence suggests that both asthma and wheezy bronchitis constitute part of one disease entity, differing only in degree (Williams and McNicol, 1969).

\section{Results}

PREVALENCE OF ASTHMA AND WHEEZY BRONCHITIS

BY THE AGE OF 11

A history of asthma with or without wheezy bronchitis was reported by parents in $3.5 \%$ of 13509 children from whom information was available relating specifically to asthma or wheezy bronchitis. A further $8.8 \%$ were reported to have a history of wheezy bronchitis only. The proportions in the year before the interview at the age of 11 are set out in Table 1 . This shows that $2 \%$ had suffered from asthma attacks during the previous year and a further $2.9 \%$ from wheezy bronchitis. One or more attacks of asthma or wheezy bronchitis a month were reported in 102 children, of whom 29 were having attacks at least once a week. Thus, 7.6 per in whom asthma or wheezy bronchitis had occurred

1000 children aged 11 were having wheezy attacks of some kind at least monthly. Eleven children were receiving special teaching because of their asthma (eight were classified as delicate and three as physically handicapped). One death had been ascribed to asthma in a girl aged 11 .

Children reported by parents to have had asthma or wheezy bronchitis in the year before the interview at the age of 11 were designated as having current attacks and comprised $4.9 \%$ of the total sample. The children whose attacks were reported to have taken place before, but not during, the preceding year, are subsequently refered to as having past attacks. This group comprised $7 \cdot 4 \%$ of the total sample and includes 29 children with a history of asthma and 51 with a history of wheezy bronchitis for whom there was no information about whether attacks had occurred in the past year. The remaining 11-year-old children $(87.7 \%)$, who had no history of asthma or wheezy bronchitis, were categorised as having neither condition.

\section{BOYS AND GIRLS}

Attacks of asthma and wheezy bronchitis, both current and past, were more common in boys than girls. This difference was more marked in the asthma group, where there were nearly twice as many boys as girls, but it was still significant in the wheezy bronchitis group (Table 2). Twenty of the $\overrightarrow{0}$ 29 children shown in Table 1 as having attacks af least weekly were boys.

Table 2 Prevalence of asthma and wheezy bronchitis by sex

\begin{tabular}{|c|c|c|c|c|c|c|}
\hline & \multicolumn{2}{|l|}{ Boys } & \multicolumn{2}{|l|}{ Girls } & \multicolumn{2}{|l|}{ Total } \\
\hline & No. & $\%$ & No. & $\%$ & No. & $\%$ \\
\hline $\begin{array}{l}\text { Asthma } \\
\text { Current attacks } \\
\text { Past attacks }\end{array}$ & $\begin{array}{l}177 \\
130\end{array}$ & $\left(\begin{array}{l}2 \cdot 6) \\
1 \cdot 9)\end{array}\right.$ & $\begin{array}{l}93 \\
69\end{array}$ & $\left(\begin{array}{l}1 \cdot 4) \\
1 \cdot 1)\end{array}\right.$ & $\begin{array}{l}270 \\
199\end{array}$ & $\left(\begin{array}{l}2 \cdot 0) \\
1 \cdot 5)\end{array}\right.$ \\
\hline $\begin{array}{l}\text { Wheezy bronchitis } \\
\text { Current attacks } \\
\text { Past attacks } \\
\text { Neither condition }\end{array}$ & $\begin{array}{r}229 \\
444 \\
5953\end{array}$ & $\begin{array}{r}3 \cdot 3) \\
6 \cdot 4) \\
(85 \cdot 9)\end{array}$ & $\begin{array}{r}165 \\
357 \\
5892\end{array}$ & 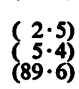 & $\begin{array}{r}394 \\
801 \\
11845\end{array}$ & $\begin{array}{l}\left(\begin{array}{r}2.9) \\
5.9\end{array}\right) \\
(87.7)\end{array}$ \\
\hline Total & 6933 & $(100)$ & 6576 & $(100)$ & 13509 & $(100)$ \\
\hline
\end{tabular}

Table 1 History of asthma and wheezy bronchitis at the age of 11 years

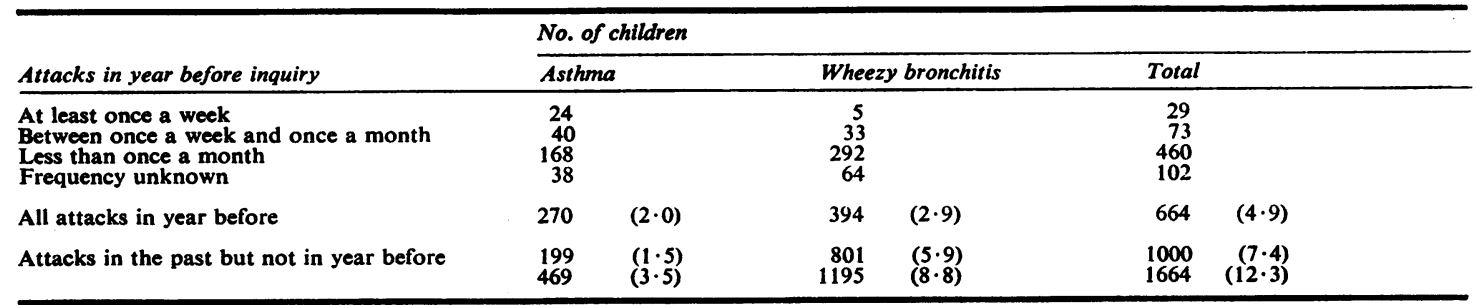

Total population $=13509$ children, of whom 11845 had no history of either condition. Percentages of total population in brackets. 
Table 3 Prevalence of asthma and wheezy bronchitis by social class

\begin{tabular}{|c|c|c|c|c|c|c|c|c|c|c|c|c|c|}
\hline & \multicolumn{4}{|c|}{ Non-manual } & \multicolumn{4}{|c|}{ Manual } & \multirow{2}{*}{\multicolumn{2}{|c|}{$\begin{array}{l}\text { No male head } \\
\text { No. } \%\end{array}$}} & \multirow[b]{2}{*}{$\begin{array}{l}\text { No } \\
\text { answer }\end{array}$} & \multirow[b]{2}{*}{$\begin{array}{l}\text { Total } \\
\text { No. }\end{array}$} & \multirow[b]{2}{*}{$\%$} \\
\hline & $\begin{array}{l}\text { I and II } \\
\text { No. }\end{array}$ & $\%$ & $\begin{array}{l}I I I \\
\text { No. }\end{array}$ & $\%$ & $\begin{array}{l}\text { III } \\
\text { No. }\end{array}$ & $\%$ & $\begin{array}{l}I V \text { and } V \\
\text { No. }\end{array}$ & $\%$ & & & & & \\
\hline \multirow{3}{*}{$\begin{array}{l}\text { Asthma } \\
\text { Current attacks } \\
\text { Past attacks } \\
\text { Wheezy bronchitis } \\
\text { Current attacks } \\
\text { Past attacks } \\
\text { Neither condition } \\
\text { Total }\end{array}$} & $\begin{array}{l}64 \\
61\end{array}$ & $\begin{array}{l}(2 \cdot 1) \\
(2 \cdot 0)\end{array}$ & $\begin{array}{l}31 \\
16\end{array}$ & $\begin{array}{l}(2 \cdot 6) \\
(1 \cdot 4)\end{array}$ & $\begin{array}{r}101 \\
84\end{array}$ & $\begin{array}{l}(1.9) \\
(1.5)\end{array}$ & $\begin{array}{l}62 \\
25\end{array}$ & 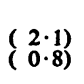 & $\begin{array}{r}10 \\
8\end{array}$ & $\left(\begin{array}{l}1 \cdot 5) \\
1 \cdot 2)\end{array}\right.$ & $\begin{array}{l}2 \\
5\end{array}$ & $\begin{array}{l}270 \\
199\end{array}$ & $\begin{array}{l}2 \cdot 0) \\
(1 \cdot 5)\end{array}$ \\
\hline & $\begin{array}{r}95 \\
177 \\
2610\end{array}$ & 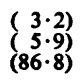 & $\begin{array}{r}35 \\
69 \\
1021\end{array}$ & 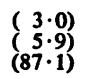 & $\begin{array}{r}154 \\
311 \\
4795\end{array}$ & 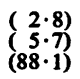 & $\begin{array}{r}78 \\
173 \\
2612\end{array}$ & 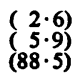 & $\begin{array}{r}24 \\
50 \\
575\end{array}$ & 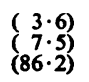 & $\begin{array}{r}8 \\
21 \\
232\end{array}$ & $\begin{array}{r}394 \\
801 \\
11845\end{array}$ & $\begin{array}{l}(2 \cdot 9) \\
(5 \cdot 9) \\
(87 \cdot 7)\end{array}$ \\
\hline & 2981 & $(100)$ & 1172 & $(100)$ & 5445 & $(100)$ & 2950 & $(100)$ & 667 & (100) & 268 & 13509 & $(100)$ \\
\hline
\end{tabular}

Comparison between non-manual and manual social classes.

Asthma (current and past) $\quad$ vs. neither condition $\chi^{2} 6.31 \mathrm{df} P<0.05$

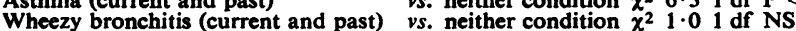

Table 4 Percentages of children with asthma and wheezy bronchitis reported as suffering from eczema and hay fever

\begin{tabular}{|c|c|c|c|c|c|}
\hline & \multicolumn{2}{|l|}{ Asthma } & \multicolumn{2}{|c|}{ Wheezy bronchitis } & \multirow[t]{2}{*}{ Neither condition } \\
\hline & Current & Past & Current & Past & \\
\hline \multirow{2}{*}{$\begin{array}{l}\text { Recurrent eczema in past } 12 \text { months } \\
\text { Recurrent hay fever/allergic rhinitis } \\
\text { in past } 12 \text { months }\end{array}$} & $23 \cdot 9 * * *$ & $13 \cdot 7^{* * *}$ & $10 \cdot 7^{* * *}$ & $4 \cdot 6$ & $3 \cdot 4$ \\
\hline & $44 \cdot 9 * * *$ & $25 \cdot 4^{* * *}$ & $25 \cdot 2^{* * *}$ & $8 \cdot 2^{*}$ & $6 \cdot 3$ \\
\hline Number of children with data & 268 & 197 & 384 & 787 & 11692 \\
\hline
\end{tabular}

Test for difference between each asthma or wheezy bronchitis group and neither condition

$\chi^{2}$ significance levels $* * * P<0.001$

$* 0.01<P<0.05$

Otherwise $<0.05<\mathrm{P}$

\section{SOCIAL CLASS}

Social class was defined according to the Registrar General's classification of fathers' occupations when this information was available and the father was the head of the household. (Registrar General, 1966). The frequency of reported asthma was significantly greater in children from non-manual families than in those from manual families, and this difference was accounted for by the higher frequency of past asthma reported in Social Classes I and II compared with Social Classes IV and V $(P<0.001)$. Social Class III was intermediate between these two (Table 3). The prevalence of wheezy bronchitis, however, showed no social class gradient.

It was interesting to find a preponderance of manual families among those whose current attacks occurred more, rather than less, frequently than once a month $(P<0.01)$.

\section{OTHER SOCIAL FACTORS}

There was no difference in family size, or in birth order within the family, between children with a history of asthma or wheezy bronchitis (current or past) and those who suffered from neither condition. Nor was there a difference in the frequency of these two conditions according to region (northern England, southern England, Wales, and Scotland), or to overcrowding (more than 1.5 persons per room), or to financial hardship in the previous year.
ECZEMA AND HAY FEVER

There was a clear association between asthma and wheezy bronchitis and other atopic conditions such as eczema and hay fever (Table 4). Children with a history of asthma were reported by their parents to have suffered from eczema and hay fever in the year before the follow-up interview significantly more often than those with a history of wheezy bronchitis only $(P<0.001)$. Nearly one in four of the children with current asthma had suffered from eczema, and nearly half from hay fever or allergic rhinitis.

\section{RECURRENT ILLNESS OR INFECTION}

A history of recurrent headaches or migraine, vomiting or bilious attacks, and abdominal pains, was significantly more frequent among children with reported wheezy bronchitis only than among those with a history of asthma or of neither condition (Table 5). Similarly, a history of recurrent throat or ear infections in the year before the interview was most frequent among children with reported wheezy bronchitis. More than twice as many children with current attacks of wheezy bronchitis had suffered from recurrent infection as had those with asthma or a negative history. The proportion of children reported to have had a tonsillectomy was similar in each group ( $22 \%)$.

PHYSICAL EXAMINATION

The medical examination findings are shown in 
Table 5 Percentages of children with asthma and wheezy bronchitis reported as suffering from recurrent illness or infections

\begin{tabular}{|c|c|c|c|c|c|}
\hline \multirow[b]{2}{*}{ Recurrent conditions in past 12 months } & \multicolumn{2}{|l|}{ Asthma } & \multicolumn{2}{|c|}{ Wheezy bronchitis } & \multirow[t]{2}{*}{ Neither condition } \\
\hline & Current & Past & Current & Past & \\
\hline $\begin{array}{l}\text { Headaches or migraine } \\
\text { Vomiting or bilious attacks } \\
\text { Abdominal pain } \\
\text { Throat and/or ear infections }\end{array}$ & $\begin{array}{r}14 \cdot 6 \\
5 \cdot 3 \\
10 \cdot 5 \\
10 \cdot 8\end{array}$ & $\begin{array}{c}15 \cdot 4 \\
1 \cdot 0^{*} \\
9 \cdot 2 \\
7 \cdot 2\end{array}$ & $\begin{array}{l}24 \cdot 7^{* * *} \\
8 \cdot 8^{* *} \\
14 \cdot 3^{*} \\
22 \cdot 7^{* * *}\end{array}$ & $\begin{array}{l}21 \cdot 3 * * * * \\
7 \cdot 2 * * * \\
14 \cdot 3 * * \\
13 \cdot 7 * *\end{array}$ & $\begin{array}{r}15 \cdot 1 \\
4 \cdot 3 \\
10 \cdot 7 \\
10 \cdot 4\end{array}$ \\
\hline Number of children with data & 267 & 195 & 388 & 788 & 11711 \\
\hline
\end{tabular}

Test for difierence between each asthma or wheezy bronchitis group and neither condition $x^{2}$ significance levels $* * * P<0.001$

$* * 0.001<P<0.01$

* $0.01<\mathrm{P}<0.05$

Otherwise $<0.05<P$

Table 6 Medical examination findings in children with asthma and wheezy bronchitis

\begin{tabular}{|c|c|c|c|c|c|}
\hline & \multicolumn{2}{|l|}{ Asthma } & \multicolumn{2}{|c|}{ Wheezy bronchitis } & \multirow[t]{2}{*}{$\begin{array}{l}\text { Neither } \\
\text { condition }\end{array}$} \\
\hline & Current & Past & Current & Past & \\
\hline & \multicolumn{5}{|c|}{ Percentages of children } \\
\hline $\begin{array}{l}\text { Bronchial spasm } \\
\text { Chest deformity }\end{array}$ & $\begin{array}{r}20 \cdot 7 \\
8 \cdot 8\end{array}$ & $\begin{array}{l}3 \cdot 3 \\
2 \cdot 7\end{array}$ & $\begin{array}{l}4.9 \\
1.9\end{array}$ & $\begin{array}{l}0.7 \\
1.4\end{array}$ & $\overline{0.6}$ \\
\hline $\begin{array}{l}\text { obstruction } \\
\text { Eczema }\end{array}$ & $\begin{array}{r}7 \cdot 2 \\
15 \cdot 5\end{array}$ & $\begin{array}{l}5 \cdot 5 \\
9 \cdot 4\end{array}$ & $\begin{array}{l}6 \cdot 3 \\
6 \cdot 0\end{array}$ & $\begin{array}{l}1.6 \\
2.9\end{array}$ & $\begin{array}{l}1.5 \\
1.6\end{array}$ \\
\hline $\begin{array}{l}\text { Number of } \\
\text { children } \\
\text { examined }\end{array}$ & 251 & 182 & 366 & 739 & 10901 \\
\hline
\end{tabular}

Table 6. More than $20 \%$ of children with current attacks of asthma had physical signs of expiratory bronchi. A 'chest deformity' (the nature of the defect was unspecified) was reported in $9 \%$ of this group. By contrast, $5 \%$ of those with current attacks of wheezy bronchitis had signs of bronchial spasm, and $2 \%$ were recorded as having a 'chest deformity'. The parents' reports of eczema were supported by the findings of the medical examination; eczema was present most frequently in children with current attacks of asthma, and it was more frequent in those with past attacks of asthma than in those with current wheezy bronchitis. The highest proportion of children with marked nasal obstruction was also in the current asthma group.

\section{HEIGHT AND WEIGHT}

Since there was no difference in mean height or weight between the asthma and wheezy bronchitis groups (allowing for sex and social class), the children with current attacks of asthma and/or wheezy bronchitis were subdivided according to whether or not attacks occurred at least once a month, or less frequently. Comparisons were then made between these two groups, the past attack group, and those with a negative history, making four groups in all. After adjustment had been made for sex and social class, because these have independent effects on height and weight, it was found that the mean height of children in the four groups did not differ significantly.

'Relative weight', that is, the weight expected for any given height, derived from the whole sample, was examined at $\mathbf{1 1}$ years of age to give a crude index of nutrition (Newens and Goldstein, 1972). Children with current attacks of asthma and/or wheezy bronchitis in whom the attacks occurred at least monthly were of significantly lower mean relative weight than children in the other three groups; on average about $4 \%$ lighter than expected.

HOSPITAL ATTENDANCE

Children with reported asthma, current or past were more likely to have attended hospital as inpatients or outpatients for investigation or treatment of their asthma than children with wheezy bronchitis alone (Table 7). More than half the children with current asthma had attended hospital for this condition, compared with $39 \%$ of those with past asthma, $27 \%$ of those with current wheezy bronchitis alone, and only $17 \%$ of those with a history of past wheezy bronchitis.

Table 7 Numbers and percentages of children with asthma and wheezy bronchitis who had attended hospital

\begin{tabular}{|c|c|c|c|c|}
\hline & \multicolumn{2}{|l|}{ Asthma } & \multicolumn{2}{|c|}{ Wheezy bronchitis } \\
\hline & Current & Past & Current & Past \\
\hline $\begin{array}{l}\text { Inpatient } \\
\text { Outpatient only } \\
\text { No attendance }\end{array}$ & $\begin{array}{r}54(20 \cdot 2) \\
91(34 \cdot 0) \\
123(45 \cdot 9)\end{array}$ & $\begin{array}{r}25(12 \cdot 8) \\
51(26 \cdot 0) \\
120(61 \cdot 2)\end{array}$ & $\begin{array}{r}28(7 \cdot 2) \\
75(19 \cdot 4) \\
284(73 \cdot 4)\end{array}$ & $\begin{array}{r}52(6 \cdot 6) \\
80(10 \cdot 2) \\
654(83 \cdot 2)\end{array}$ \\
\hline $\begin{array}{l}\text { Number of } \\
\text { children with } \\
\text { data }\end{array}$ & $268(100)$ & $196(100)$ & $387(100)$ & $786(100)$ \\
\hline
\end{tabular}

\section{ABSENCE FROM SCHOOL}

Children with current attacks of both asthma and wheezy bronchitis were frequently absent from school because of ill health in the year preceding the inquiry. Nearly $50 \%$ of the children suffering more than one attack a month had missed at least 
four weeks of school during that year; $13 \%$ of this group had been absent for more than three months. Although these children comprised only $0.8 \%$ of the whole sample, they accounted for $12 \%$ of the 11-year-olds who missed more than three months of school during the year before the follow-up interview. The children with past attacks of asthma and of wheezy bronchitis alone missed no more school than children with a negative history.

\section{EDUCATIONAL ATTAINMENTS}

In spite of time away from school because of illness, children with current attacks of asthma and wheezy bronchitis appeared to keep up with their school work. As there was no difference between the mean reading scores of girls and boys with asthma and those with wheezy bronchitis, comparisons of educational attainment were made between the group suffering current attacks of either condition (again subdivided according to whether attacks had occurred at least monthly or less frequently), the group with past attacks, and those who had no history of either condition. In an analysis of variance allowing for sex and social class, the mean reading comprehension test score was not significantly different in any of the four groups. Similar findings were observed from an analysis based on mean scores obtained in an arithmetic test.

\section{EMOTIONAL AND BEHAVIOURAL}

\section{FACTORS AT HOME}

On the modified Rutter home behaviour scale (Essen and Peckham, 1976), which reflects the parental view of the child's behaviour, children with current and past attacks of asthma and wheezy bronchitis had significantly higher mean scores than those with a negative history, indicating an adverse result. This difference persisted after allowance had been made for sex and social class in an analysis of variance, and children with current attacks occurring at least monthly had the highest mean scores, followed by children who had less frequent attacks, children with past attacks, and those with a negative history.
Although behavioural disturbances such as bedwetting have been reported more commonly in asthmatic than in non-asthmatic children, there was no evidence from the present study to support this finding.

SOCIAL ADJUSTMENT AT SCHOOL

Social adjustment at school was measured by the Bristol social adjustment guide. A high score is considered by the author of the test to be associated with poor adjustment in school, and a low score with good adjustment. Children with current attacks of asthma or wheezy bronchitis had significantly higher scores than those with past attacks or with neither condition $(P<0.01)$. amounting to about half the sex difference and social class difference in adjustment. Allowance was then made, in an analysis of variance, for differences in social class, and particularly in sex, as boys generally obtain higher scores than girls. The difference in mean social adjustment score between these groups was less marked and no longer statistically significant at the $5 \%$ level.

\section{INFORMATION ABOUT BOTH CONDITIONS AT BOTH AGES}

Relevant data were accumulated for 11914 children at the ages of seven and 11. Table 8 shows the prevalence of asthma with or without wheezy bronchitis, and of wheezy bronchitis alone, at both ages.

Slightly more than $3 \%$ of children were reported to have had one or more attacks of asthma, with or without wheezy bronchitis, during their first seven years. At the age of $11,43 \%$ of these children were reported to be still suffering from attacks of asthma, and a further $7 \%$ from attacks of wheezy bronchitis only. The remaining $50 \%$ were reported free of wheezing.

At the age of seven, a further 1800 children (15\%) were reported to have had one or more attacks of wheezy bronchitis, but not asthma. At the age of 11, only $13 \%$ of this group were currently suffering from asthma or wheezy bronchitis and the remaining

Table 8 Numbers and percentages of children with asthma and wheezy bronchitis at seven and 11 years of age

\begin{tabular}{|c|c|c|c|c|c|c|c|c|c|c|c|c|}
\hline & \multicolumn{12}{|c|}{ History at 11 years of age } \\
\hline & \multicolumn{4}{|l|}{ Asthma } & \multicolumn{4}{|c|}{ Wheezy bronchitis } & \multirow{2}{*}{\multicolumn{2}{|c|}{$\begin{array}{l}\text { Neither } \\
\text { condition }\end{array}$}} & \multirow{2}{*}{\multicolumn{2}{|c|}{ Total }} \\
\hline & Current & & Past & & Current & & Past & & & & & \\
\hline $\begin{array}{l}\text { History at seven years of ag } \\
\text { Asthma with or without } \\
\text { wheezy bronchitis } \\
\text { Wheezy bronchitis only } \\
\text { Neither condition }\end{array}$ & $\begin{array}{r}160 \\
42 \\
36\end{array}$ & $\begin{array}{r}(43 \cdot 0) \\
(2 \cdot 3) \\
(0 \cdot 4)\end{array}$ & $\begin{array}{r}104 \\
27 \\
16\end{array}$ & $\begin{array}{l}(28 \cdot 0) \\
(1 \cdot 5) \\
(0 \cdot 2)\end{array}$ & $\begin{array}{r}26 \\
192 \\
129\end{array}$ & 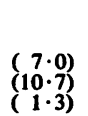 & $\begin{array}{r}34 \\
407 \\
222\end{array}$ & $\begin{array}{r}(9 \cdot 4) \\
(22.6) \\
(2 \cdot 3)\end{array}$ & $\begin{array}{rr} & 47 \\
1 & 132 \\
9 & 339\end{array}$ & $\begin{array}{l}(12 \cdot 6) \\
(62.9) \\
(95 \cdot 8)\end{array}$ & $\begin{array}{r}371 \\
1800 \\
9742\end{array}$ & $\begin{array}{l}(100) \\
(100) \\
(100)\end{array}$ \\
\hline
\end{tabular}


$87 \%$ were free from wheezing. The parents of twothirds of this group reported at the interview at the age of 11 that their children had never suffered from asthma or wheezy bronchitis. The attacks reported at the age of seven may well have occurred early in life, or have been so mild that parents could not remember them; especially as four years elapsed between the two sets of interviews.

A history of asthma or wheezy bronchitis was reported at the age of 11 in $4 \%$ of children who had no history of either condition at the age of seven. Of those children whose wheezing had apparently developed between the ages of seven and 11, a total of 36 were reported to have current asthma, and 129 current wheezy bronchitis only.

\section{Discussion}

In a survey of Kent schoolchildren aged between five and 14, the frequency of asthma reported by parents was $3 \cdot 8 \%$. Children with a positive history were found to have significantly lower peak expiratory flow rates than children with no history, showing that it is possible to detect children with impaired ventilatory function from a history of asthma (Hamman et al., 1975). In the present study, in which the diagnosis of asthma and wheezy bronchitis was also based on parental reporting, $3.5 \%$ of children aged 11 had a history of asthma and $8.8 \%$ a history of wheezy bronchitis.

In the year before the 11-year follow-up, $4.9 \%$ of children in the present study were reported to have suffered from asthma $(2 \%)$ or wheezy bronchitis $(2.9 \%)$. A history of wheezy bronchitis at this age is likely to indicate true bronchospasm rather than a symptomatic wheeze which may occur in young children suffering from respiratory infections. Comparable findings were reported among Birmingham schoolchildren aged six to 15 , of whom $5.5 \%$ had experienced one or more wheezy complaints in the previous six months (Smith et al., 1971). Similarly, in a population of 10-to-15-yearold schoolchildren in Aberdeen, the prevalence of asthma was $4.8 \%$ (Dawson et al., 1969). In a random sample of 10-year-old schoolchildren in Australia, $11 \%$ had a history of episodes of asthma and wheezing, and $3.7 \%$ had continuing asthma at the age of 10 (Williams and McNicol, 1969).

Our study confirms the increased prevalence of asthma in males (Graham et al., 1967; Dawson et al., 1969; Williams and McNicol, 1969; Smith et al., 1971; Hamman et al., 1975). The increase was more marked in children who suffered more frequent attacks, and was greater among children with a history of asthma than among those with a history of wheezy bronchitis.
The influence of social and environmental factors has been the subject of conflicting reports. In the present study, a history of asthma was more common among children from non-manual families than among those from manual families, whereas a history of wheezy bronchitis was not related to social class. Hamman et al. (1975) and Graham and his colleagues (1967) also found an excess of children with asthma among Social Classes I and II. In Australia, McNicol et al. (1973) found no difference between asthmatic children and a control group according to father's occupation. However, Mitchell and Dawson (1973) reported an excess of severe asthma in children from Social Classes IV and V and they also found that children with severe attacks tended to come from large families regardless of social class.

There has been much controversy over the relationship between asthma and wheezy bronchitis. Most recent studies suggest that the two conditions are inseparable, the diagnosis most probably reflecting the severity of the symptoms (Williams and McNicol, 1969). In the present study, however, certain differences did emerge. Not only were children with a history of asthma suffering from a more severe condition, which was reflected in the findings at medical examination, but they were also more likely to have suffered from eczema or has fever. Recurrent headaches or migraine, recurren vomiting or bilious attacks, and recurrent ear of throat infections, however, were more common among the children with a history of wheezy bronchitis than among those with asthma. It is possible that a diagnosis of asthma is more likely to be made in the presence of an associated atopic condition which may reflect a poorer prognosis (Blair, 1977).

The personalities of asthmatic children and their reactions to emotional stress are sometimes considered to be important factors in the aetiology of asthma. Few population studies have examined this, and where a positive association has been reported between asthma and psychological disturbance, samples have been highly selectivefor example, children attending hospital. In the present study, children with asthma showed poorer adjustment at school than non-asthmatic children, but this difference was not significant when allowance had been made for social class and sex. This underlines the need to make the requisite adjustments for background factors when attempting to define the characteristics of asthmatic children.

Investigation of home behaviour, which reflected the parental view of the child's behaviour, gave a different picture. The asthmatic group, and 
particularly those having frequent attacks, had poorer home behaviour than non-asthmatic children, even after allowing for sex and social class. This finding may be due to the greater tendency of parents, rather than teachers, to over-protect the asthmatic child. Neuhaus (1965) examined children attending public schools in New York and found that asthmatics were more maladjusted, neurotic, and dependent than non-handicapped children, but no more than children with cardiac disorders. This suggests that asthmatic children have no characteristic personality patterns but show personality traits similar to those of other children with chronic illness.

Some studies have reported higher than average educational attainments among children with asthma or wheezy bronchitis (Graham et al., 1967; Mitchell and Dawson, 1973). Others have found no such association (Rawls et al., 1971), and this was so in the present report. However, $13 \%$ of the children who had suffered from wheezing attacks at least monthly had missed at least three months schooling in the preceding year, and it is possible that their educational attainments might have been higher if they had not missed so much school.

Over half the children reported to be wheezing at the age of 11 had never attended hospital, where full investigation, including identification of allergens and assessment of respiratory function in response to therapy, should be carried out. A great deal can now be done to prevent chronic respiratory damage resulting from contact with harmful allergens; for example, regular or intermittent medication with antispasmodics or disodium cromoglycate. There is still a tendency to assume that children will 'grow out' of asthma, but this does not seem to be so, since half of the children with a history of asthma at the age of seven were still suffering attacks four years later.

We are grateful to Mr Harvey Goldstein for carrying out the statistical analyses, to Miss Parrendar for help in the preparation of the paper, and to our colleagues at the National Children's Bureau for their helpful comments. This work was supported by grants to the National Children's Bureau from the Department of Health and Social Security and the Department of Education and Science.

Reprints from: Dr Catherine Peckham, Charing Cross Hospital Medical School, London W6.

\section{References}

Blair, H. (1977). National history of childhood asthma. Archives of Disease in Childhood, 52, 613-619.

Butler, N. R., and Alberman, E. D. (1969). Perinatal Problems. Livingstone: Edinburgh.

Davie, R., Butler, N. R., and Goldstein, H. (1972). From birth to seven. Longman: London.

Dawson, B., Horobin, G., Illsey, R., and Mitchell, R. (1969). A survey of childhood asthma in Aberdeen. Lancet, 1, 827-830.

Essen, J., and Peckham, C. S. (1976). Nocturnal enuresis in childhood. Developmental Medicine and Child Neurology, 18, 577-589.

Graham, P. J., Rutter, M. L., Yule, W., and Pless, T. B. (1967). Childhood asthma: a psychosomatic disorder? Some epidemiological considerations. British Journal of Preventive and Social Medicine, 21, 78-85.

Hamman, R. F., Halil, T., and Holland, W. W. (1975). Asthma in schoolchildren. British Journal of Preventive and Social Medicine, 29, 228-238.

McNicol, K. N., Williams, H.E., Allan, J., and McAndrew, I. (1973). Spectrum of asthma: psychological and social components. British Medical Journal, 4, 16-20.

Mitchell, R. G., and Dawson, B. (1973). Educational and social characteristics of children with asthma. Archives of Disease in Childhood, 48, 467-471.

Neuhaus, E. C. (1965). A personality study of asthmatic and cardiac children. Psychosomatic Medicine, 20, 181-186.

Newens, M. E., and Goldstein, H. (1972). Height, weight and the assessment of obesity in children. British Journal of Preventive and Social Medicine, 26, 33-39.

Rawls, D. J., Rawls, J. R., and Harrison, C. W. (1971). An investigation of six to eleven-year old children with allergic disorders. Journal of Consulting and Clinical Psychology, 36, 260-264.

Registrar General (1966). Classification of occupations. HMSO: London.

Rutter, M., Tizard, J., and Whitmore, K. (1970). Education, Health and Behaviour. Longman: London.

Smith, J. M., Harding, K., and Cumming, G. (1971). The changing prevalence of asthma in schoolchildren Clinical Allergy, 1, 56-61.

Start, K. B., and Wells, B. K. (1972). The trend of reading standards. National Foundation for Educational Research: Slough.

Stott, D. H. (1963). The social adjustment of children. Manual to the Bristol social adjustment guides. University of London Press.

Williams, H. E., and McNicol, K. N. (1969). Prevalence, natural history and relationship of wheezy bronchitis and asthma in children: an epidemiological study. British Medical Journal, 4, 321-325. 